\title{
Exploitation of resources and cardiovascular outcomes in low-risk patients with chest pain hospitalized in coronary care units
}

This article was published in the following Dove Press journal:

International Journal of General Medicine

17 October 2011

Number of times this article has been viewed

\author{
Habibollah Saadat' \\ Hossein Shiri ${ }^{2}$ \\ Zahra Salarpour ${ }^{2}$ \\ Tahereh Ashktorab ${ }^{2}$ \\ Hamid Alavi Majd ${ }^{2}$ \\ Zahra Saadat' \\ Hosein Vakili'
}

'Cardiovascular Research Center, Modarres Hospital, Shaheed Beheshti University of Medical Sciences, Tehran ${ }^{2}$ Nursing School, Shaheed Beheshti University of Medical Sciences, Tehran, Iran
Correspondence: Hosein Vakili Cardiovascular Research Center, Modarres Hospital, Shaheed Beheshti University of Medical Sciences, Saadat-Abad Ave, PO Box I9978744II, Tehran, Iran Tel +982122083106 $\mathrm{Fax}+982122083106$ Email hosavak@yahoo.com
Background: Most patients who present to medical centers due to chest pain do not suffer from acute coronary syndromes and do not need to be hospitalized in coronary care units (CCUs). This study was done to determine exploitation of resources and cardiovascular outcomes in low-risk patients with chest pain hospitalized in CCUs of educational hospitals affiliated with a major medical university.

Methods: Over a 4-month period, 550 patients with chest pain who were hospitalized in the CCUs belonging to six hospitals affiliated to the authors' medical university were recruited by census method. Using Thrombolysis in Myocardial Infarction risk score, 95 patients $(17.27 \%)$ were categorized as low-risk patients. This group was evaluated with respect to demographics, bed occupancy rate, mean hospitalization period, expenses during admission, and cardiovascular outcomes in the 30-day period postdischarge.

Results: Mean ( \pm standard deviation) hospitalization duration was $3.04( \pm 0.71)$ days. No significant difference was seen between the six surveyed hospitals regarding hospitalization duration $(P=0.602)$. The highest bed occupancy rate was seen in Taleghani and Shohada Tajrish hospitals and the lowest was in Modarres Hospital. The mean paid treatment expenses by lowrisk patients was IRR 2,050,000 (US\$205). Mean total hospitalization expenses was US\$205. No significant difference was seen between the six surveyed hospitals $(P=0.699)$. Of the patients studied, $89.5 \%$ did not show any cardiovascular complications in 1 month and no deaths occurred.

Conclusion: Given the high bed-occupancy rate by low-risk patients, associated high hospitalization costs, and the lack of cardiovascular complications in patients observed at 1-month follow-up after discharge, it is recommended that appropriate evaluations be performed in emergency units to prevent unnecessary admissions.

Keywords: bed occupancy, hospitalization expenses, low-risk patients, chest pain, exploitation of resources

\section{Introduction}

Annually, more than 7 million patients with chest pain present to emergency departments in the USA. However, of these patients, $75 \%$ do not have cardiac-related chest pain. ${ }^{1}$ Evaluation and treatment of these patients imposes a cost of more than US\$10 billion on the US health system. ${ }^{2}$ In Iran, a frequent number of beds in coronary care units (CCUs) are occupied by low-risk patients with suspected diagnosis of acute coronary syndromes (ACSs). In 2003, Azizi et al found that approximately $70 \%$ of these patients did not have deterioration of their symptoms during their hospitalization and were discharged after 2-3 days. ${ }^{3}$ At the same time that these CCU beds were occupied by low-risk patients, $2 \%-8 \%$ of patients with chest pain who actually had ACS were discharged. ${ }^{4}$ In a study of 903 patients with acute chest pain, it was found that patients stayed an average of 
3.01 days in CCU and that this hospitalization duration was associated with: the diagnosis of acute myocardial infarction and unstable angina, severity of complications, the use of invasive and noninvasive diagnostic methods, and primary triage for referring patients to CCUs. ${ }^{5}$ Factors such as time of admission, insurance coverage, cardiac monitoring, exercise tests, and echocardiography had effects on increasing the length of the patients' stay period..$^{5}$ The results of another study have shown that the probability of occurrence of serious complications in low-risk patients is much less than high-risk patients. ${ }^{6}$ Gatein et al have shown that patients with a normal electrocardiogram without chest pain can be observed without cardiac monitoring and there is no indication for the admission of such patients to CCU. ${ }^{7}$

The current study was done in 2008, the data were collected this year, to determine the rate of exploitation of resources and cardiovascular outcomes in low-risk patients with chest pain in CCUs of hospitals affiliated to a major medical university in Tehran, Iran.

\section{Methods and materials}

In this descriptive study, 550 patients with chest pain who were hospitalized in the CCU of six affiliated general hospitals of Shahid Beheshti University of Medical Sciences, Tehran, Iran, were recruited by census method during a 4-month period. The statistics of the surveyed hospitals in 2008 are presented in Table 1.

Using the Thrombolysis in Myocardial Infarction (TIMI) risk score, 95 patients were identified as low risk (17.27\%), $110(21.5 \%)$ as moderate risk, and $336(61 \%)$ as high risk. The low-risk group was evaluated with respect to demographics, bed-occupancy rate (BOR), mean hospitalization period, expenses during admission to $\mathrm{CCU}$, and cardiovascular outcomes in the 30-day period postdischarge.

For gathering the required information, inclusion criteria, based on the TIMI score provided by the American College of Cardiology for the categorizing of patients with chest pain, and patient medical records were used simultaneously. The inclusion criteria consisted of disease information, admission to duration of stay in CCU, the expenses of hospitalization, and cardiovascular outcomes.

The TIMI score uses seven independent risk factors:

1. Age $\geq 65$ years

2. Presence of three or more coronary artery disease (CAD) risk factors

3. Established CAD on angiography

4. Use of aspirin for at least 1 week

5. Occurrence of angina at least twice in a recent 24-hour period

6. ST segment deviation of $0.5 \mathrm{~mm}$ or more

7. Increase in cardiac enzymes.

Patients are categorized according to their scores into low risk (TIMI score $<3$ ), moderate risk (TIMI score 3-5), and high risk (TIMI score $>5$ ).

For determination of the validity of TIMI scores and information gathered according to the inclusion criteria, the content validity method was applied. For reliable testing of TIMI, the interobserver reliability method was used; risk rate was determined in this way and, after ten observations, an acceptable rate of 0.80 was achieved.

\section{Ethics statement}

Since this study was based on medical records of the surveyed hospitals and no diagnostic or therapeutic intervention was performed on patients, there was no medical ethics approval and no need to obtain informed consent, either written or verbal, from any patient.

\section{Results}

Mean ( \pm standard deviation) hospitalization duration in the low-risk group was $3.04( \pm 0.71)$ days (range, 1-4 days) (Table 2). Using analysis of variance (ANOVA),

Table I The statistics of the six surveyed hospitals

\begin{tabular}{|c|c|c|c|c|c|c|}
\hline & Taleghani & Shohada Tajrish & Modarres & Imam Hossein & Loghman & Torfe \\
\hline Number of beds & 389 & 330 & 262 & 497 & 360 & 87 \\
\hline Bed occupancy (\%) & 78 & 7I & 55.9 & 80.3 & 77.9 & 43.6 \\
\hline Mean admission (days) & 7.1 & 6.3 & 6.8 & 6.6 & 4 & 2.6 \\
\hline Deaths per 1000 discharges & 24.91 & 37.8 & 35.82 & 33.11 & 22.42 & 0.7 \\
\hline Bed occupancy cycle delay (days) & 2 & 2.5 & 5.4 & 1.6 & I.I & 3.4 \\
\hline Outpatient presentation per day & 241 & 176 & 139 & 418 & 262 & 189 \\
\hline $\begin{array}{l}\text { Total number of emergency } \\
\text { presentations }\end{array}$ & 26,904 & 29,499 & 24,956 & 33,359 & 34,883 & 30,819 \\
\hline CCU beds & 8 & 8 & 21 & 20 & 7 & 21 \\
\hline
\end{tabular}

Abbreviation: $\mathrm{CCU}$, coronary care unit. 
Table 2 Frequency distribution of low-risk patients with chest pain admitted to six surveyed hospitals and the duration of their hospitalization

\begin{tabular}{llll}
\hline Hospital & $\begin{array}{l}\text { Number } \\
\text { of low-risk } \\
\text { patients }\end{array}$ & $\begin{array}{l}\text { Hospitalization } \\
\text { (days) }\end{array}$ & $\begin{array}{l}\text { Bed } \\
\text { occupancy (\%) }\end{array}$ \\
\hline $\begin{array}{l}\text { Taleghani } \\
\text { Shohada }\end{array}$ & $19(20 \%)$ & $3.26( \pm 0.733)$ & 16 \\
Tajrish & $19(20 \%)$ & $2.9( \pm 0.788)$ & 16 \\
Modarres & $6(6.3 \%)$ & $3( \pm 0.632)$ & 5 \\
Imam & $17(17.9 \%)$ & $3( \pm 0.845)$ & 14 \\
Hossein & & & 15 \\
Loghman & $18(19 \%)$ & $3.11( \pm 0.676)$ & 13 \\
Torfe & $16(19 \%)$ & $2.94( \pm 0.556)$ & 13.1 \\
Total & $95(100 \%)$ & $3.04( \pm 0.713)$ & 13 \\
\hline
\end{tabular}

Notes: The data in brackets are presented as mean (standard deviation).

no significant difference was seen between the six hospitals regarding hospitalization duration $(P=0.602)$. The highest BOR by low-risk patients was seen in Taleghani and Shohada Tajrish hospitals and the lowest was in Modarres Hospital (Table 2).

Mean paid treatment expenses by low-risk patients was IRR2,050,000 (US\$205). Mean total hospitalization expenses was US\$205 (range, 129-240) (Table 3). In patients who had insurance, $90 \%$ of hospitalization expenses were paid by insurance companies. Using ANOVA, no significant difference was seen between the six surveyed hospitals $(P=0.699)$. In terms of cardiovascular outcomes, the majority of patients $(89.5 \%)$ at 1-month follow-up did not have any cardiac complications and six cases $(6.3 \%)$ presented to emergency departments due to chest pain and were discharged after receiving outpatient treatment and four cases (4.2\%) were readmitted to CCU. At the 1-month follow-up of low-risk patients, no deaths were documented.

\section{Discussion}

In the six surveyed hospitals, of 550 patients who were hospitalized in CCUs with the diagnosis of acute coronary syndromes, 95 cases $(17.5 \%)$ were low risk and their mean hospitalization duration was 3.04 days. In Udvarhelyi et al's

Table 3 Frequency distribution of patients in six surveyed hospitals according to treatment expenses

\begin{tabular}{lll}
\hline Hospital & $\begin{array}{l}\text { Range (minimum-maximum) } \\
\text { (US\$) }\end{array}$ & $\begin{array}{l}\text { Mean } \\
\text { (US\$) }\end{array}$ \\
\hline Taleghani & $\mid 72-240$ & 212 \\
Shohada Tajrish & $|29-23|$ & 200 \\
Modarres & $|72-23|$ & 205 \\
Imam Hossein & $129-23 \mid$ & 203 \\
Loghman & $\mid 72-230$ & 207 \\
Torfe & $165-232$ & 203 \\
\hline
\end{tabular}

study, mean hospitalization period was reported as 3.01 days, which is in agreement with the present study. ${ }^{5}$

One of the reasons that BOR was the lowest at Modarres Hospital is that the hospital is a specialty hospital for patients with cardiac disorders.

Mean treatment expenses of the patients studied was US\$205, whereas in Udvarhelyi et al's study, hospitalization expenses were reported as US\$2375. In the Sirois and Pimental study, the mean triage expenses of patients in emergency departments was US $\$ 189 .{ }^{6}$ The high cost of unnecessary hospitalization of low-risk patients and increased cost to insurance systems can be reduced by the prevention of hospitalization of such patients.

In the current study, at 1-month follow-up no deaths occurred. Similarly, in Solinas et al's study, at 1-month follow-up after discharge from emergency unit, ACS was seen in 5.2\% (three acute myocardial infarction cases) but no deaths were reported. ${ }^{8}$ In the present study, the fact that there was no cardiovascular complications in $89.5 \%$ of patients at 1-month follow-up shows that the studied patients were not high risk and were not indicated for admission to CCUs. TIMI scores were useful in the diagnosis of low-risk CAD patients.

None of the surveyed hospitals had chest pain units in their emergency departments. Additionally, they did not have any special guidelines for triage of patients with chest pain. As a result of this ineffective approach, a considerable number of low-risk patients were admitted to the limited CCU facilities, which should be reserved for the treatment of high-risk patients.

\section{Conclusion}

Since special care is expensive and requires expert personnel, patients should be categorized according to their treatment needs and those in critical condition should be prioritized for admission to CCUs.

\section{Acknowledgments}

Funding for this study was provided by Shahid Beheshti University of Medical Sciences, Tehran, Iran.

\section{Disclosure}

The authors declare no conflicts of interest in relation to this paper.

\section{References}

1. Eslick GD. Classification, natural history, epidemiology, and risk factors of noncardiac chest pain. Dis Mon. 2008;54(9):593-603.

2. Chan GW, Sites FD, Shofer FS, Hollander JE. Impact of stress testing on 30-day cardiovascular outcomes for low-risk patients with chest pain admitted to floor telemetry beds. Am J Emerg Med. 2003;21(4) $282-287$. 
3. Azizi F, Hatami H, Janghorbani M, eds. Epidemiology and Control of Common Disorders in Iran [Persian]. 2nd ed. Tehran: Eshtiagh Press; 2003.

4. Siebens K, Moons P, De Geest S, Miljoen H, Drew BJ, Vrints C. The role of nurses in a chest pain unit. Eur J Cardiovasc Nurs. 2007;6(4):265-272.

5. Udvarhelyi IS, Goldman L, Komaroff AL, Lee TH. Determinants of resource utilization for patients admitted for evaluation of acute chest pain. J Gen Intern Med. 1992;7(1):1-10.

6. Sirois JG, Pimentel L. Prognostic value of the emergency department cardiogram for in-hospital complications of acute myocardial infarction [corrected]. Ann Emerg Med. 1993;22(10):1568-1572.
7. Gatien M, Perry JJ, Stiell IG, Wielgosz A, Lee JS. A clinical decision rule to identify which chest pain patients can safely be removed from cardiac monitoring in the emergency department. Ann Emerg Med. 2007;50(2): 136-143.

8. Solinas L, Raucci R, Terrazzino S, et al. Prevalence, clinical characteristics, resource utilization and outcome of patients with acute chest pain in the emergency department. A multicenter, prospective, observational study in north-eastern Italy. Ital Heart J. 2003;4(5):318-324.

\section{Publish your work in this journal}

The International Journal of General Medicine is an international, peer-reviewed open-access journal that focuses on general and internal medicine, pathogenesis, epidemiology, diagnosis, monitoring and treatment protocols. The journal is characterized by the rapid reporting of reviews, original research and clinical studies across all disease areas.
A key focus is the elucidation of disease processes and management protocols resulting in improved outcomes for the patient.The manuscript management system is completely online and includes a very quick and fair peer-review system. Visit http://www.dovepress.com/ testimonials.php to read real quotes from published authors.

Submit your manuscript here: http://www.dovepress.com/international-journal-of-general-medicine-journal 